\title{
The ischemic area-at-risk on T2-weighted MRI shows recovery of systolic strain at 1 year
}

\author{
Declan P O'Regan, Ben Ariff*, Clare Neuwirth, Yvonne Tan, Giuliana Durighel, Stuart A Cook \\ From 2011 SCMR/Euro CMR Joint Scientific Sessions \\ Nice, France. 3-6 February 2011
}

\section{Introduction}

Animal models have demonstrated a recovery in systolic strain following reperfusion of acutely ischemic myocardium, however this has not been shown in clinical practice.

\section{Purpose}

We aimed to determine whether there was long term improvement of regional strain in acutely ischemic myocardium following primary coronary intervention using cardiac magnetic resonance imaging (CMR)

\section{Methods}

We studied 16 patients with acute ST elevation myocardial infarction (STEMI) who had received successful primary coronary intervention (PCI) to the culprit coronary artery. CMR was performed on a $1.5 \mathrm{~T}$ Philips Achieva system (Best, Netherlands) within 7 days of PCI and again at 1 year. We used segmentation of T2weighted spectrally-selective inversion recovery (SPIR) imaging to detect the ischemic area-at-risk and delayed enhancement inversion recovery imaging to measure infarct size and transmural thickness. Complementary spatial modulation of magnetization (CSPAMM) tagging with harmonic phase analysis (HARP) was used to measure peak midwall systolic strain at baseline and followup. Each section was divided according to the American Heart Association classification providing a total of 96 myocardial segments for analysis at each visit.

\section{Results}

All patients showed acute myocardial edema within the reperfused territory and a variable transmural extent of enhancing necrosis. Mean myocardial salvage, given as the proportion of viable myocardium within the ischemic

Imperial College, London, UK

C 2011 O-Regan et al; licensee BioMed Central Ltd. This is an open access article distributed under the terms of the Creative Commons Attribution License (http://creativecommons.org/licenses/by/2.0), which permits unrestricted use, distribution, and reproduction in any medium, provided the original work is properly cited. area-at-risk, was $62 \pm 21 \%$ at baseline. The mean infarct area at baseline was $20 \pm 10.2 \%$ and $14 \pm 5.7 \%$ at 1 year follow-up. In total 45 segments showed enhancing necrosis and the peak systolic midwall circumferential strain (Ecc) improved between baseline and follow-up $(-14.4 \pm 5.3 \%$ vs $-19.2 \pm 5.4 \%, \mathrm{p}<0.0001)$. In the remaining non-infarcted 45 segments there was no change in Ecc $(-18.7 \pm 6.8 \%$ vs $-21.1 \pm 6.1 \%$, NS). The mean radial transmural extent of necrosis showed no correlation with $\Delta \mathrm{Ecc}\left(\mathrm{r}^{2}=0.01, \mathrm{NS}\right)$.

\section{Conclusions}

These findings demonstrate a long-term improvement in systolic function in acutely ischemic reperfused myocardium.

Published: 2 February 2011

\section{doi:10.1186/1532-429X-13-S1-P90}

Cite this article as: O'Regan et al:: The ischemic area-at-risk on T2weighted MRI shows recovery of systolic strain at 1 year. Journal of Cardiovascular Magnetic Resonance 2011 13(Suppl 1):P90.

Submit your next manuscript to BioMed Central and take full advantage of:

- Thorough peer review

- No space constraints or color figure charges

- Immediate publication on acceptance

- Inclusion in PubMed, CAS, Scopus and Google Scholar

- Research which is freely available for redistribution
- Convenient online submission 